\title{
Inter-relações entre culturas, tecnicidade e cidadania na obra de Jesús Martín-Barbero
}

\section{Inter-relations among cultures, technicity and citizenship in the work of Jesús Martín-Barbero}

\author{
J I A N A DRIANA BONIN ${ }^{a}$ \\ Universidade do Vale do Rio dos Sinos, Programa de Pós-Graduação em Ciências da Comunicação. São \\ Leopoldo - RS, Brasil
}

\section{RESUMO}

O texto objetiva reconstruir os modos como Jesús Martín-Barbero problematiza os nexos entre cultura, cidadania e tecnicidade, refletindo sobre sua contribuição para a pesquisa contemporânea dedicada a esta problemática. Na reflexão do pesquisador o campo da cultura, em suas imbricações com a tecnicidade, é pensado como espaço crucial de constituição da conflitividade social e de emergência de novas figuras de cidadania. A tecnicidade opera como dimensão estruturante destes processos, em articulações socioculturais complexas e multidimensionais. Suas propostas continuam oferecendo bases produtivas para pensar estas questões e nos convocam também a considerar outros aspectos que se afiguram nos ambientes e nas culturas digitais na atualidade.

Palavras-chave: Martín-Barbero, cidadania, tecnicidade, identidades culturais, comunicação cidadã

\begin{abstract}
The text aims to reconstruct the ways that Jesús Martín-Barbero problematizes the links between culture, citizenship and technicity, bringing some reflections on his contribution to the contemporary research dedicated to this question. In the researcher's reflection, the culture field, in its imbrications with the technicity, is conceived as a crucial space of constitution of social conflictivity and emergency of new citizenship figures. The technicity operates as a structural dimension of these processes, in complex and multidimensional sociocultural articulations. His proposals continue to offer productive bases for thinking these issues and also invite us to consider other aspects that emerge in today's digital environments and cultures.
\end{abstract}

Keywords: Martín-Barbero, citizenship, technicity, cultural identities, citizen communication 


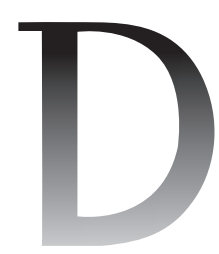

${ }^{1}$ Trata-se da edição publicada pela editora Gustavo Gili, Barcelona, em 1987

(Lopes, 2018).

${ }^{2}$ Esta inflexão é demarcada nas introduções às reedições posteriores da obra Dos meios às mediações, publicadas pelo Convênio Andrés Bello, Bogotá, em 1998 e pela Universidade Federal do Rio de Janeiro (UFRJ), Rio de Janeiro, em 2001 (Lopes, 2018).

${ }^{3}$ Para comemorar os 30 anos do livro Dos meios às mediações, a revista MATRIZes publicou, em 2018, um dossiê intitulado Jesús Martín Barbero: 30 anos De los medios a las mediaciones, dedicado à sua obra. Textos deste dossiê foram aproveitados para compor as reflexões aqui desenvolvidas. No mesmo ano a revista Intexto publicou um dossiê intitulado Mediações, trajetos e ensinamentos: tributo a Jesús Martín-Barbero, fruto de um colóquio realizado no Programa de Pós-Graduação em Comunicação da Universidade Federal do Rio Grande do Sul (PPGCOM-UFRGS) no final

de novembro de 2017, para comemorar os 30 anos da obra já referida, do qual participamos.

Os debates acompanhados também alimentaram as reflexões deste texto.

\section{INTRODUÇÃO}

$\mathrm{N}$ O PENSAMENTO DE Jesús Martín-Barbero, pesquisador de contribuição transcendente no campo comunicacional latino-americano, encontramos reflexões instigantes para pensar as inter-relações entre cultura e cidadania no contexto contemporâneo, vinculadas à expansão e penetração dos meios de comunicação nas sociedades e aos processos de globalização. Destas reflexões, aqui nos interessam aquelas realizadas posteriormente à primeira edição de sua obra seminal, De los medios a las mediaciones, lançada em 1987, quando a problemática dos meios passa a ser gradativamente ressituada. Este reposicionamento vai tomando forma mais definida a partir de textos posteriores, que incorporam a tecnicidade como mediação, até assumi-la como dimensão estruturante das sociedades. Tal movimento começa a se expressar no pensamento de Martín-Barbero quando o mapa das mediações culturais da comunicação, proposto naquela mesma obra ${ }^{1}$, é revisto, dando origem a outro, o das mediações comunicativas da cultura, explicitado em um novo prólogo para a reedição daquele livro ${ }^{2}$. Nesse primeiro movimento, o pesquisador inclui a tecnicidade no conjunto das mediações redesenhadas. Em textos posteriores, ela adquire ainda mais centralidade e passa a ser pensada como dimensão estrutural das sociedades, em afinidade com as transformações impulsionadas pelos meios e, mais contemporaneamente, pela digitalização.

Pensando a partir do cenário latino-americano, Martín-Barbero concebe, nesse movimento, que o campo da cultura (sempre no cerne de suas reflexões desde a obra de 1987), ao ser atravessado pelos processos de globalização e estruturalmente constituído pela tecnicidade, se apresenta como espaço crucial de constituição da conflitividade social e de emergência de novas figuras de cidadania na contemporaneidade.

Por considerarmos que estas reflexões continuam nos interpelando e oferecendo chaves produtivas para pensar tais questões, pretendemos neste texto sistematizar as propostas do pesquisador para ponderar as interconexões entre culturas, tecnicidade e cidadania ${ }^{3}$. Junto deste movimento de resgate, procuramos também trazer alguns aportes para refletir sobre suas contribuições à pesquisa contemporânea dedicada a estas problemáticas.

Para dar conta deste objetivo, realizamos uma pesquisa teórica em textos do autor que tratam estas questões, publicados posteriormente à obra De los medios a las mediaciones, entre os anos 1997 e 2018. A seleção que fizemos inclui livros, textos publicados em coletâneas organizadas por outros pesquisadores e em revistas científicas digitais a que tivemos acesso e que tratam de questões relevantes para a problemática que nos interessa. Privilegiamos, neste 
movimento, os textos escritos pelo próprio autor como aposta para recuperar, do seu pensamento, tais questões. Nossas proposições se nutriram também de aportes contemporâneos relativos às mídias digitais para complementar e debater as propostas do autor.

No itinerário deste texto percorreremos inicialmente os modos como a obra do autor problematiza as inter-relações entre culturas, tecnicidade e cidadania. Nossa trilha seguirá, num segundo movimento, pelas reflexões que ele empreende sobre o espaço público e as mídias digitais em vínculo com a cidadania. Na última parte da caminhada, traremos algumas reflexões sobre a contribuição da abordagem barberiana para investigar este campo de problemáticas, apontando também alguns aspectos que merecem ser considerados para atualizar e ampliar as proposições do autor, relativas a questões emergentes no âmbito das mídias digitais.

\section{CULTURAS, COMUNICAÇÃO E CIDADANIA NO PENSAMENTO DE JESÚS MARTÍN-BARBERO}

O tratamento das inter-relações entre culturas, comunicação e cidadania ganha particular inflexão na trajetória do pensamento de Martín-Barbero quando o autor passa a reconhecer que a mediação tecnológica vai se convertendo numa dimensão-chave, até tornar-se estruturante nas sociedades. É desse percurso da reflexão do autor que trataremos nesta primeira parte do texto.

As inter-relações entre meios de comunicação e culturas no contexto da América Latina são um tema-chave ao longo das várias obras do autor e vão ganhando novas configurações neste trajeto. Estas reformulações se vinculam à sua posição epistêmica de cartógrafo, que confere movimento a suas reflexões em afinidade com as transformações sociais, sobretudo no campo da comunicação. Assim, sua obra se vê marcada, como bem assevera Lopes (2018), por um

permanente processo de complexificação... [sendo configurada por] movimentos de avanços e retomadas, de sistematizações parciais, sempre incompletas, ao modo de arquipélagos móveis que reunidos, mostram o continente de uma teoria viva em estreito diálogo com as transformações do seu contexto, que é a América Latina inserida no mundo. (p. 41)

Está presente nas reflexões que analisamos a preocupação do pesquisador em se distanciar de propostas redutoras da complexidade da realidade e do papel dos meios nela. Em De los medios a las mediaciones, sua concepção desafia visadas epistêmicas que entendem a comunicação somente a partir dos meios. 


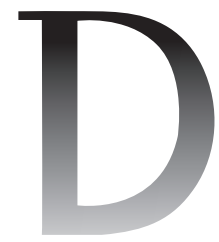

${ }^{4}$ De modo geral, essa leitura que fazemos converge para aquelas realizadas por Lopes

(2018) e Jacks e Schmidt (2018), em seus textos sobre a obra do autor.

Estudamos o tratamento destas problemáticas nas seguintes obras: MartínBarbero, 2001, 2002, 2006, 2009a, 2009b, 2009c, 2009d, 2010a, 2010b, 2010c, 2010d, 2014a, 2014b, 2018.
Sua proposta de entender os processos comunicacionais a partir das mediações articuladoras das diferentes instâncias do processo revela uma postura que contesta o mediacentrismo, enfrentando concepções tanto inscritas no funcionalismo como no estruturalismo-marxismo. Isso não significa, em nosso entendimento, que ele tenha deixado de considerar o relevante papel social dos meios, como certas críticas posteriores apontariam, mas que buscava pensá-los numa perspectiva que não reduzisse as multidimensionalidades constitutivas dos processos comunicacionais ${ }^{4}$.

Mais recentemente, ao pensar a técnica, seu embate se dá com concepções que, no seu dizer, apresentam uma "nefasta combinação entre determinismo tecnológico e pessimismo cultural" (Martín-Barbero, 2014, p. 17). Assim, sua posição epistemológica procura problematizar de modo mais amplo a técnica, construir um olhar complexo e multiperspectivado para desafiar a razão dualista com que fomos acostumados a pensá-la - reflexão que embasa o progressivo adensamento da concepção de mediação tecnicidade.

Para situar nosso itinerário na obra do autor, é interessante voltar a De los medios a las mediaciones, livro lançado em 1987. Nele o pesquisador concebe a cultura como dimensão-chave para compreender os processos comunicacionais latino-americanos. A cultura é pensada, entre outros aspectos, como uma mediação crucial nas inter-relações das pessoas com as mídias. Nutrido por uma perspectiva histórica e transdisciplinar, Martín-Barbero reflete sobre os processos que vinculam os meios de comunicação ao campo cultural latino-americano e sobre seu papel estratégico na construção da hegemonia. O autor atenta também para as múltiplas formas de vinculação, resistência e réplica constituídas a partir do campo cultural que desafiam, conferem dinamismo e instauram contradições nos processos de construção da hegemonia.

Ao longo dos anos constatamos nos textos estudados ${ }^{5}$ que, em afinidade com as mudanças no cenário latino-americano, o autor procura compreender com acuidade as redefiniç̧̃es do campo cultural impulsionadas pela globalização, pelas mídias e, mais recentemente, pelas novas tecnologias da comunicação. A dimensão midiática ganha maior relevo, centralidade e densidade epistêmica em textos mais recentes, do fim dos anos 1990. Nesta linha de reflexão, MartínBarbero passa a considerar que um novo sistema técnico se consolida em escala planetária, transformando vários âmbitos, entre eles a experiência espaço-temporal das sociedades. A técnica, ao aprofundar sua presença e inserção social, converte-se num elemento estruturante de nossas realidades.

A técnica - que durante séculos foi considerada como mero instrumento ou utensílio, ou seja, algo sem a menor densidade cognitiva transformou radicalmente seu 
status, tornando-se uma dimensão estrutural das sociedades contemporâneas, ao mesmo tempo em que adquire densidade simbólica e cultural ${ }^{6}$. (Martín-Barbero, 2009d, p. 22, grifo nosso)

Este reconhecimento da centralidade da técnica nas sociedades vai se alinhando progressivamente ao pensamento de outros investigadores latino-americanos que, no final da década de 1990, passam a considerar que, no processo de expansão e penetração sistêmica das mídias nas sociedades, elas vão adquirindo um papel central, configurador dos mais variados campos e domínios da experiência. Tal perspectiva indica que este câmbio de época é mais produtivamente pensado como um processo de midiatização das sociedades ${ }^{7}$. Ainda assim, em nosso entendimento, um dos elementos de originalidade da reflexão do autor se encontra na insistência em levar em conta as mediações que articulam complexamente os processos midiáticos a dimensões comunicacionais e societais.

Na compreensão de Martín-Barbero, a técnica alcança contemporaneamente uma penetração sistêmica e transversal, conformando um novo entorno tecnocomunicativo $^{8}$ que impregna visceralmente o mundo da vida. A complexidade e a imbricação social que os meios alcançam são pensadas a partir da ideia de constituição de um ecossistema comunicativo abrangente, ainda que apresente desiguais modos de ação e diferenciados usos e apropriações sociais. A tecnicidade configura, nesse contexto, novos modos de percepção, novas linguagens, sensibilidades e escrituras. Neste cenário, o autor reflete que o lugar da cultura na sociedade se altera "quando a mediação tecnológica da comunicação deixa de ser meramente instrumental para espessar-se, adensar-se e converter-se em estrutural" (2002, p. 225).

Esta linha compreensiva, que consideramos produtiva para pensar os processos contemporâneos de midiatização social, se aproxima das reflexões de Sodré (2006) sobre a constituição contemporânea de um bios midiático, impulsionado pelas tecnologias digitais. Trata-se de uma esfera imiscuída na realidade social e configuradora de ethos midiatizados, entendidos como costumes, condutas, cognições e percepções marcados pelo atravessamento das mídias.

Nessa progressão de seu pensamento, a reflexão do autor sobre a ação das tecnologias de comunicação, vinculadas à globalização, mantém a complexidade da mirada, procurando examinar suas contradições como cenário dinamizador de transformações para o campo das culturas, suas perversidades e possibilidades.

No âmbito das perversidades, em relação às dimensões econômicas, a globalização promove a penetração dominadora do mercado na sociedade, aumentando a pobreza e a desigualdade social. O cenário nacional, como articulador das dimensões políticas, econômicas e culturais das sociedades, se
${ }^{6}$ No original: "la técnica - que fue durante siglos considerada como mero instrumento o utensilio, es decir, algo desprovisto de la menor densidad cognitiva ve ahora transformado su estatus radicalmente, pasando a constituirse en dimensión estructural de las sociedades contemporáneas a la vez que se llena de densidad simbólica y cultural". Esta e demais traduções da autora.

${ }^{7}$ É o caso de pesquisadores como Verón (1997) e Mata (1999), que propõem, no final da década de 1990, a noção de midiatização para entender as transformações relativas ao papel dos meios nas sociedades.

${ }^{8}$ A noção de entorno tecnocomunicativo, como explicita Martín-Barbero em entrevista a Mariluce Moura, publicada na revista Pesquisa Fapesp, se alimenta do pensamento de Javier Echeverría sobre o terceiro entorno. O primeiro entorno, habitado pelos seres humanos, seria o natural; o segundo e o terceiro, criados pelos seres humanos, são respectivamente o urbano e o tecnocomunicativo (MartínBarbero, 2009e). 


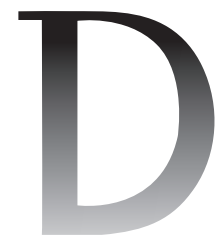

${ }^{9}$ Martín-Barbero (2014a) observa que um dos traços mais marcantes da globalização, na sua fase de aprofundamento neoliberal na

América Latina, é o divórcio crescente entre Estado e sociedade. Isto porque o Estado tem dificuldade em responder às demandas sociais, por estar pressionado e vigiado pelas instituições de unificação econômica global.

${ }^{10}$ No original: "Lo que galvaniza hoy a las identidades como motor de lucha es inseparable de la demanda de reconocimiento y de sentido. Y ni el uno ni el otro son formulables en meros términos económicos o políticos, pues ambos se hallan referidos al núcleo mismo de la cultura, en cuanto mundo del pertenecer a y del compartir con. Razón por la cual la identidad se constituye hoy en la fuerza más capaz de introducir contradicciones en la hegemonía de la razón instrumental". debilita, assim como as fronteiras entre nacional e local ${ }^{9}$. No campo cultural, impulsionadas pela ação dos meios de comunicação e, mais recentemente, pelas tecnologias digitais, as lógicas de mundialização da cultura infiltram-se nas práticas cotidianas das pessoas, gerando mudanças profundas em suas condições de vida. Entre suas consequências estão as reconfigurações das identidades, impulsionadas por transformações estruturais vinculadas ao descentramento das sociedades, à fragmentação das paisagens culturais e à multiplicação de referentes de identificação. Estes processos impelem mudanças profundas nas condições de vida das culturas locais, indígenas, negras, regionais, de gênero, entre outras.

Assim a globalização, combinada à ação sistêmica dos meios, acelera o desenraizamento das identidades ao inscrevê-las nas lógicas e fluxos do mercado e desativar suas complexidades e seus aspectos conflitivos. Os meios de comunicação e as tecnologias de informação convertem-se em produtores de mundialização cultural ao introduzir referentes que representam estilos e valores desterritorializados (Martín-Barbero, 2003, 2010b). Os fenômenos de convergência, simultaneidade e aceleração do tempo, dinamizados pelas novas tecnologias, também passam a modelar a experiência temporal das sociedades, pressionando-as a se instalar em um presente contínuo e colaborando para produzir experiências efêmeras. A aceleração temporal dilui o poder delimitador e normativo da tradição e sua capacidade de contribuir para projetar o futuro das sociedades.

Por outro lado, no âmbito das possibilidades, o autor concebe que estes processos vêm impulsionando, entre outros fenômenos, um reavivamento de identidades, que funcionam como espaços de pertença estratégicos para introduzir contradições nas lógicas da globalização:

O que galvaniza hoje as identidades como motor de luta é inseparável da demanda por reconhecimento e sentido. E nem um, nem o outro, são formuláveis em termos meramente econômicos ou políticos, pois ambos se encontram relacionados ao próprio núcleo da cultura, enquanto mundo de pertencer a e de compartilhar com. Razão pela qual a identidade se constitui hoje na força mais capaz de introduzir contradições na hegemonia da razão instrumental ${ }^{10}$. (Martín-Barbero 2009b, pp. 3-4)

$\mathrm{Na}$ América Latina, as comunidades culturais vão se convertendo, neste cenário, em âmbito chave para reconstituir o sentido das coletividades, reinventar suas identidades, renovar os usos de suas memórias e patrimônios, promover a articulação produtiva entre o local e o global. Elas representam a emergência 
de novas figuras de cidadania, que atuam e buscam construir estratégias de empoderamento a partir da cultura.

Novos movimentos sociais (como os étnicos, de gênero e ecológicos) emergem neste contexto e lutam para ser socioculturalmente reconhecidos, como argumenta o autor, "cidadaneamente' visíveis em sua diferença; o que dá espaço a um novo modo de exercer politicamente seus direitos, pois a nova visibilidade catalisa o surgimento de novos indivíduos políticos" (MartínBarbero, 2009a, para. 1). Eles evidenciam a dificuldade das instituições liberais democráticas de darem conta da diversidade cultural e apontam a necessidade de uma política de extensão de direitos para todos os setores da população (Martín-Barbero, 2009c).

Essas tendências descortinadas nas reflexões do autor têm se manifestado nas sociedades, mas apresentam contornos diversos nos contextos e conjunturas de cada país, região e mesmo localidade, os quais precisam ser considerados. Vivenciamos contemporaneamente cenários marcados pelo avanço do neoliberalismo, por inflexões políticas à direita em países latino-americanos como o Brasil, por novas formas de repressão, controle e criminalização dos movimentos sociais. Estes são alguns dos aspectos que nossas investigações precisam concretamente problematizar para atualizarmos as reflexões do autor.

Martín-Barbero concebe a comunicação como dimensão constitutiva da vida das culturas; nas suas palavras, "uma cultura somente está viva quando é capaz de comunicar, ou seja, de intercambiar e interagir com outras culturas" (2009c, p. 155). Argumenta também que a narração é constitutiva das identidades culturais. Nesta via de reflexão, ele nos oferece chaves importantes para pensar o reconhecimento social e político das identidades: a necessidade de serem narradas socialmente, em suas complexidades e contradições; as possibilidades de aproveitar e combinar diferentes formas de relato, a diversidade de idiomas e a criatividade expressiva presentes nos grupos, coletivos e comunidades sociais com as múltiplas possibilidades comunicativas abertas pelas experiências midiáticas contemporâneas.

Para que a pluralidade das culturas do mundo seja politicamente considerada, é indispensável que a diversidade de identidades possa ser contada, narrada. Isso tanto em cada um dos seus "idiomas" quanto na "linguagem intermediadora" que hoje os atravessa por meio do movimento das "traduções e hibridações" do oral com o escrito, o audiovisual com o hipertextual - e de uma interculturalidade na qual as dinâmicas da economia e da cultura-mundo mobilizam não somente a heterogeneidade dos grupos e sua readequação às pressões do global, como também a coexistência de códigos e relatos muito diversos no interior de uma mesma 
sociedade, abalando assim a experiência que tínhamos até agora de identidade. (Martín-Barbero, 2009c, p. 156)

Essa relação entre comunicação e cultura se acentua atualmente a partir das mudanças impulsionadas pela rede tecnológica de comunicação, que afetam a percepção das comunidades sobre si mesmas e seus modos de construir identidades. Esse cenário representa para as comunidades uma ameaça à sobrevivência de suas culturas, mas também uma oportunidade para romper com a exclusão e reinventar perspectivas de futuro. Assim, a globalização e as novas tecnologias abrem portas para as lutas por ampliação da cidadania, possibilitando a mistura de culturas num cenário de emergência social de outras cosmovisões que desafiam a hegemonia do racionalismo ocidental. A expansão das novas tecnologias e sua progressiva apropriação por setores sociais subalternos renovam as chances de construção de uma contra-hegemonia pelo mundo.

\section{CIDADANIA, COMUNICAÇÃO E TECNOLOGIAS DIGITAIS}

Nos textos de Martín-Barbero (2002, 2009b, 2010b), outra questão que recuperamos para problematizar aspectos da cidadania vinculada ao campo comunicacional diz respeito às ligações entre comunicação e espaço público. A comunicação é pensada por ele como dimensão constitutiva do espaço público, esfera vinculada àquilo que é próprio a todos na sociedade e que recebe a maior publicidade possível. O público constitui o espaço cidadão, articulando interesses comuns e promovendo a interação comunicativa. É cenário de circulação de interesses e discursos plurais, heterogêneos e deveria possibilitar o reconhecimento da diversidade de posições sociais. A comunicação, neste âmbito, teria o papel de expor os temas em controvérsia e suas distintas interpretações, permitindo a deliberação pública e o acesso ao debate social.

Os meios de comunicação tornaram-se ambientes constituintes da vida pública e do reconhecimento social. Eles são fundamentais para ampliar ou restringir o público, que passa a ser constituído por suas gramáticas, lógicas e operações. O público se amplia quando é possível atores diversos serem reconhecidos, quando a sociedade civil pode se expressar na sua pluralidade, quando se qualificam as compreensões dos cidadãos acerca de seus problemas e/ou das orientações dos governantes, quando sua constituição se concretiza a partir de uma isonomia cidadã. Restringe-se o público quando há distorções de informações, banalização de processos, superficialidade no tratamento da 
complexidade do social, diluição da argumentação e da conversação, predomínio de lógicas comerciais (Martín-Barbero, 2002, 2010b).

Para o pesquisador, o reconhecimento recíproco é um elemento fundamental na constituição da cidadania e se vincula aos direitos de informar e ser informado, de falar e ser escutado, imprescindíveis à participação nas decisões da coletividade. Assim, a despossessão do direito a ser visto e ouvido - que equivale a existir/contar socialmente, tanto no terreno individual como no coletivo - é uma forma evidente de exclusão cidadã.

Para que o reconhecimento das diversidades culturais se efetive, MartínBarbero (2009b) reflete que certos direitos precisam ser ampliados nas sociedades, entre eles: o direito à participação, como capacidade de intervenção das comunidades e dos cidadãos nas decisões que afetam suas vidas, o que se vincula à necessidade de informação confiável, na qual predomine o interesse comum sobre o negócio; o direito à expressão, nos meios massivos e comunitários, de todas as culturas e sensibilidades que compõem a ampla diversidade dos países latino-americanos.

Pensando a situação da América Latina, ele constata certos avanços nas relações entre cidadania e comunicação, particularmente em dois planos que qualificam o público. O primeiro diz respeito ao crescimento e à potencialização de meios comunitários cidadãos, que colaboram para constituir uma rede cidadã de espaço público para debater tudo aquilo que não cabe nos meios privados e extrapola o local. O segundo plano é representado pelas oportunidades que a internet trouxe para a constituição de espaços de interação cidadã vinculada à troca de experiências, ao compartilhamento de visões de mundo e de propostas em articulações globais/locais.

Ao considerar o papel das redes digitais nesses processos, Martín-Barbero procura considerar suas complexidades, sendo simultaneamente

abertas e fechadas, integradoras e desintegradoras, totalizantes e destotalizantes, nicho de implantação em que convivem e se misturam lógicas, velocidades e temporalidades tão diversas como as que entrelaçam as narrativas do oral com a intertextualidade das escrituras e as intermedialidades do hipertexto ${ }^{11}$. (2010b, p. 49)

Ele atenta também para o fato de que a revolução tecnológica vem colaborando para agravar as desigualdades entre setores sociais, culturas e países. As redes digitais, na sua perspectiva, não são ambientes apenas dominados pelos direcionamentos e pelo sentido que o mercado capitalista procura dar à internet, embora essa dimensão não possa ser desconsiderada,

\footnotetext{
${ }^{11}$ No original: “abiertas y cerradas, integradoras y desintegradoras, totalizadoras y destotalizantes, nicho y despliegue em el que conviven y se mesclan lógicas, velocidades y temporalidades tan diversas como las que entrelazan las narrativas do oral con la intertextualidad de las escrituras y las intermedialidades del hipertexto".
} 


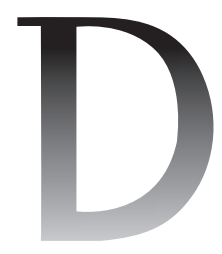

Inter-relações entre culturas, tecnicidade e cidadania

porque efetivamente é parte de sua inteligibilidade. Por um lado, tais redes potencializam modificações e hibridações entre o público e o privado, superpondo-os e diluindo suas fronteiras; por outro, promovem a visibilidade das culturas ao abrir renovadas alternativas de expressão que desafiam o poder excludente da letra.

Encontramo-nos ante uma mutação tecnológica que passou a configurar um novo ecossistema comunicativo. Ecossistema em que a experiência audiovisual, afetada pela revolução digital, aponta para a constituição de uma visibilidade cultural, cenário estratégico hoje de uma batalha política decisiva contra o velho e excludente poder da letra que ao longo de um século e meio ignorou a diferença e a riqueza das oralidades e visualidades culturais, estas que entrelaçam agora suas memórias nos imaginários da virtualidade para dar sentido novo e forma nova às tradições culturais. (Martín-Barbero, 2014a, p. 25)

A nosso ver, nessa reflexão o pesquisador oferece uma chave produtiva para pensar os potenciais das novas tecnologias de comunicação para a experimentação e produção de novos relatos que incorporem múltiplas estéticas e possibilidades de expressão, capazes de aproveitar a criatividade social e as competências comunicativas diversas dos sujeitos.

As redes são também lugar de emergência de um tecido social e de um espaço público remodelados, marcados por novas formas de sociabilidade. Elas participam das atuais condições de entrelaçamento do social com o cultural e o político, de formação da opinião pública e de exercício da cidadania. Inauguram possibilidades de ampliação do discurso público e da criatividade social vinculada à participação cidadã. Também mobilizam “'a imaginação’ social das coletividades, potencializando suas capacidades de sobrevivência e de associação, de protesto e de participação democrática, de defesa de direitos sociopolíticos e culturais e de ativação de sua criatividade expressiva” (MartínBarbero, 2009c, p. 154).

Ainda sobre as tecnologias digitais, o autor considera inovador o fato de serem relacionais e cooperativas, o que pode viabilizar a ampliação da inteligência coletiva a partir de novos modos de produção de conhecimentos que as redes digitais incentivam. Ele adverte, apropriadamente, que esta modalidade de produção coletiva de conhecimentos esteve historicamente presente em comunidades e grupos sociais na América Latina (por exemplo, os saberes médicos, pictóricos e culinários dos indígenas). Entretanto, as redes digitais têm permitido usos em que esta produção vai além daqueles modos presentes tradicionalmente nas comunidades, inaugurando oportunidades de criar saberes 
partilhados que desafiam históricas exclusões e brechas cognitivas socialmente constituídas (Martín-Barbero, 2010c, 2014b).

Essas oportunidades são relevantes para a cidadania, cujo exercício depende de informação e conhecimento. Nesse sentido, o autor reconhece a constituição de espaços para cultivar uma cultura política emancipatória renovada, vinculada à circulação de informações e ao acesso ampliado a elas, principalmente nas redes digitais: comunidades se apropriam das redes para transformar suas experiências em relatos, aproveitando as possibilidades abertas pela convergência entre as oralidades e memórias culturais e as novas linguagens, escrituras e narrativas emergentes através da tecnicidade digital.

Em nossa visão, estas reflexões do autor apontam possibilidades concretas que as tecnologias digitais inauguram em termos de sua apropriação cidadã. Entretanto, não podemos desconsiderar a persistência de obstáculos a esta efetiva apropriação. Permanecem contradições nas regulações da internet e em sua concretização, bem como restrições de acesso à rede, que ainda não é universal. Há também empecilhos ao efetivo domínio de competências tecnológicas para atuar, as quais não estão presentes de modo igualitário entre as pessoas. Persistem certas lógicas das culturas digitais que não favorecem usos cidadãos das tecnologias, e isto se soma aos interesses de corporações que dominam o mundo digital e se materializam em definições ordenadoras de plataformas de redes, recursos e aplicativos ofertados. Constituem-se processos de vigilância e controle com finalidades geopolíticas e comerciais que entram em contradição com as possibilidades emancipatórias abertas pela digitalização. Estes, entre outros fatores, concorrem para restringir possibilidades de apropriação das mídias digitais e de expressão, experimentação e ampliação dos conhecimentos de sujeitos, comunidades, grupos e movimentos sociais. É interessante considerar, ainda, que no próprio campo da pesquisa há hoje legislações éticas que, movidas pela intenção de proteger os cidadãos, acabam dificultando, quando não inibindo, o acesso e o compartilhamento de saberes e relatos de comunidades e grupos sociais com os pesquisadores.

Voltando às propostas de Martín-Barbero (2011), ao refletir sobre os desafios da investigação latino-americana no campo das inter-relações entre culturas, cidadania e tecnicidade no contexto da digitalização, ele aponta dois âmbitos que desempenham um papel decisivo na construção do futuro das sociedades. O primeiro diz respeito às experiências constitutivas dos sujeitos comunicantes contemporâneos, vinculadas às novas relações entre estética e política que estão possibilitando a reinvenção da política e de seu sentido emancipador. Estas questões estão relacionadas à transmedialidade e à convergência, fenômenos que remetem a duas novas ordens de processos e práticas. A transmedialidade 


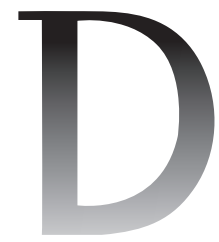

${ }^{12}$ No original: "la transmedialidad produce una convergencia de innovación e incluso de invención que hace nacer a la vez nuevas cosas y nuevos usuarios".

${ }^{13}$ No original: "nuevas formas de la experiencia que transforman los regímenes de lo sensible, o sea de la percepción y el afecto, del pensamiento y la palabra. Que es por donde pasan los caminos de la emancipación social, a la vez cultural y política".

${ }^{14}$ No original: "las nuevas prácticas y hábitos sociales colaborativos: nuevos modos de relación con, nuevas dinámicas de reapropiación de lo viejo, nuevas formas de hibridación de contenidos y géneros". está associada a um novo modo de interação dos meios, gêneros e formatos com os sensórios relativos às sonoridades, oralidades e visualidades que contagiam as linguagens, redefinindo fronteiras e possibilitando o aparecimento de narrativas e escrituras híbridas: "a transmedialidade produz uma convergência de inovação e, inclusive, de invenção que gera ao mesmo tempo novas coisas e novos usuários"12 (Martín-Barbero, 2011, p. 457). Já a convergência emerge dos usos sociais, cuja criatividade inaugura configurações do sensível. Dialogando com Rancière (2005), ele aponta, como aspecto inovador no campo da arte e das técnicas, a diluição de fronteiras que colocavam o produtor de comunicação e o receptor, a arte e o expectador em polos diferentes. A tecnicidade digital vincula-se a "novas formas de experiência que transformam os regimes do sensível, ou seja, da percepção e do afeto, do pensamento e da palavra. Que é por onde passam os caminhos da emancipação social, ao mesmo tempo cultural e política"13 (Martín-Barbero, 2011, p. 453-454).

Essas transformações se expressam no campo da cidadania, entre outras formas, nos modos como os sujeitos atuam e se fazem visíveis, materializando e encarnando a cidadania em performances, estas “'artes em ação' que, saindo dos espaços e tempos da arte, viram do avesso as memórias e expressões culturais ao evidenciar que elas, mais que produtos, são experiências e que juntam memória e invenção" (Martín-Barbero, 2009a, para. 3). Assim, as festas, os ritos e a teatralidade das passeatas tornam-se parte constitutiva das ações cidadãs, "das revanches sociais, das resistências culturais, das sabotagens políticas, das transfusões das identidades ou das subversões estéticas" (2009a, para. 3). A nosso ver, estas reflexões oferecem subsídios frutíferos para pensar os modos como atualmente coletivos, grupos e novos movimentos sociais vêm construindo suas formas de se expressar, de se fazerem visíveis e de lutar pela cidadania, misturando linguagens diversas, performances e expressividades renovadas.

O segundo âmbito referido pelo autor para a construção do futuro das sociedades refere-se aos desafios e oportunidades para mudar os modelos de educação colocados pela convergência tecnológica e pela transmedialidade. Entre estes desafios estaria o de desenvolver culturas participativas que considerem e promovam as múltiplas habilidades e competências dos sujeitos e sua criatividade expressiva nos processos de aprendizagem. Neste sentido, o autor recupera a reflexão do pesquisador argentino Alejandro Piscitelli sobre a presença e a atuação de polialfabetismos, nos quais o que importa não são propriamente os novos suportes, mas “as novas práticas e hábitos sociais colaborativos: novos modos de relação com, novas dinâmicas de reapropriação do velho, novas formas de hibridização de conteúdos e gêneros"14 (Martín-Barbero, 2011, p. 460). Nesse eixo de reflexão, a educação emerge 
também como elemento chave para a construção da cidadania e inclui pensar estrategicamente as inter-relações com as mídias nos processos comunicativos em perspectiva cidadã. Consideramos esta ótica do autor instigante para alicerçar processos educomunicativos renovadores, tanto na sala de aula como nos diversos cenários sociais (coletivos, comunidades, movimentos, grupos culturais), de modo que as competências comunicativas, expressivas e estéticas dos sujeitos sejam valorizadas, assim como as experimentações e a criatividade nas apropriações midiáticas e digitais para a formação de um olhar crítico sobre a realidade e para a construção da cidadania.

\section{CONCRETIZAÇÕES E DESAFIOS RELATIVOS ÀS PROPOSTAS DE MARTÍN-BARBERO}

As propostas trabalhadas por Martín-Barbero aqui recuperadas continuam oferecendo chaves produtivas e instigantes para pensar os processos contemporâneos de midiatização nas suas articulações com culturas e cidadania. Como pensamento em processo, suas reflexões vão dando maior centralidade à mediação tecnicidade como dimensão abrangente, que atravessa transversalmente as múltiplas dimensões sociais. Seu olhar epistêmico cartográfico, sensivelmente conectado aos processos concretos dos países, permite-lhe pensar processualmente as inter-relações entre tecnicidade e emergência de novas cidadanias no campo cultural em perspectiva complexa, que procura considerar multidimensionalidades constituintes destas interconexões, descortinar contradições e também possibilidades que aí se afiguram.

Para concretizar questões e ampliar as reflexões de Martín-Barbero, consideramos produtivo situar alguns aspectos advindos de pesquisas e problematizações recentes relacionadas aos processos comunicacionais digitais. Peruzzo (2018) oferece um primeiro subsídio ao sistematizar e refletir sobre resultados de investigações relativas aos usos das mídias digitais por coletivos, grupos e movimentos sociais contemporâneos. Em sua análise, a pesquisadora demonstra que a internet e as redes sociais digitais têm colaborado para: difundir conteúdos e informações estratégicas para embasar ações cidadãs; promover o compartilhamento de significados e gerar sentimento de pertença entre os membros; dar visibilidade a propostas, demandas e reinvindicações; estabelecer interlocuções ampliadas com a sociedade; articular manifestações públicas nos processos de convocação, mobilização e coordenação de ações. As perspectivas trazidas pela comunicação digital têm favorecido o desenvolvimento de articulações locais/ globais entre coletivos e movimentos, colaborando para estabelecer e consolidar redes de movimentos sociais. 


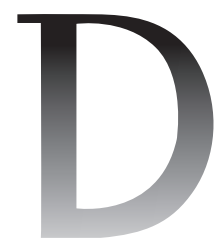

Inter-relações entre culturas, tecnicidade e cidadania

Outros investigadores apontam que o avanço das redes digitais tem impulsionado também quebras de restrições impostas a informações confidenciais, políticas, econômicas e protegidas por direitos autorais (Moglen, 2012), além de viabilizar a constituição de coberturas noticiosas plurais e a experimentação de novas modalidades de jornalismo cidadão, distintas daquelas realizadas pelas mídias hegemônicas (Marchezan, 2016).

Entretanto, para dimensionar adequadamente os ambientes digitais e suas contradições de maneira a complementar e atualizar as reflexões do pesquisador aqui investigadas, é necessário levar em conta que determinados processos vinculados ao capitalismo internacional têm levado ao estabelecimento de monopólios que controlam os fluxos de serviços e dados dos usuários de plataformas digitais. A tendência de concentração de propriedade e negócios em um número reduzido de grupos econômicos transnacionais no ciberespaço, alimentada pela privatização de ambientes tecnológicos e de recursos que, em sua origem, ofereciam acesso público e gratuito, prejudica a concorrência e favorece a invasão da privacidade dos usuários (Peruzzo, 2018). Como bem advertiu Silveira (2006), a "concentração de poder comunicacional na sociedade da informação poderá ser muito maior do que a ocorrida com a mídia de massas na sociedade industrial" (p. 79).

Associadas a isso surgem e aprofundam-se novas modalidades de monitoramento, vigilância e controle no ambiente digital, assentadas no pirateio de dados dos usuários e no seu tratamento e uso para modelar e performar o comportamento dos consumidores, a fim de que o Estado e interesses políticos e ideológicos controlem os cidadãos, como bem apontam Mattelart e Vitalis (2015), Bruno (2008) e Silveira (2006). Pesquisas recentes vêm demonstrando como essas formas de vigilância e controle restringem a construção e o exercício da cidadania. Por exemplo, a investigação de Albuquerque (2018) revela, entre outros aspectos, que o uso de redes digitais por movimentos sociocomunicacionais de Porto Alegre serviu para criminalizar sujeitos desses movimentos. Pesquisa exploratória desenvolvida no final de $2018 \mathrm{com}$

${ }^{15}$ Trata-se de pesquisa exploratória em andamento, realizada por Bruna Lapa Guia, doutoranda sob nossa orientação que está investigando os usos digitais das redes sociais por coletivos vinculados ao movimento de mulheres de Porto Alegre. integrantes de movimentos de mulheres de Porto Alegre ${ }^{15}$ aponta também que esses movimentos começam a repensar suas estratégias comunicacionais, redefinindo e restringindo o uso de redes sociais dadas as possibilidades de criminalização que se afiguram na nova conjuntura brasileira instaurada com o governo Bolsonaro.

A nosso ver, é necessário considerar também outros aspectos da realidade digital contemporânea quando pensamos na cidadania digital, entre os quais: os algoritmos e filtros que limitam significativamente as chances de interações ampliadas nas redes e de acesso a informações diversas (Pariser, 2012); 
a manipulação artificial de conteúdos por meio de robôs e outros mecanismos de replicação para acelerar sua disseminação; usos antiéticos e anticívicos das redes, como na disseminação de fake news, produzidas pelo uso deliberado da desinformação como estratagema de poder e de controle cidadão; participação desqualificada nos ambientes digitais (conteúdos banais, falsos, difamatórios); tendências ao personalismo e ao individualismo em detrimento do espírito coletivo (Peruzzo, 2018). Apesar de avanços significativos, as sociedades continuam apresentando diferenças e limitações no acesso às mídias digitais por parte das pessoas e nas competências digitais para seu domínio e apropriação.

Diante dos contextos contemporâneos, enfatiza-se a necessidade de pensar complexamente o papel das mídias digitais para a construção de processos comunicacionais cidadãos, sem reduzir tais processos à dimensão tecnológica nem superdimensioná-la, esforço para o qual nos convida a perspectiva epistêmica de Martín-Barbero. A nosso ver, é fundamental levar em conta as imbricações multidimensionais dos processos midiáticos e comunicacionais na construção da cidadania. É nesse sentido que caminha a pesquisa realizada por Castells (2013), ao descobrir que os movimentos ocorridos em países árabes, incluindo Tunísia e Egito, e na Espanha (Os Indignados), além do Occupy Wall Street deflagrado nos Estados Unidos, não se construíram somente nas redes digitais, mas em conexões comunicativas multimodais. Nesta mesma direção, a investigação de Porto (2019) sobre os processos comunicacionais dos Pataxós da Bahia é expressiva de como se vinculam redes sociocomunicacionais historicamente constituídas com as apropriações digitais da rede social Facebook, num tecido comunicativo multidimensional que congrega as lutas pataxós para a construção de cidadania.

Essas são algumas das tantas questões que continuam a desafiar a pesquisa empírica no sentido de avançar na compreensão dos nexos entre mídias, culturas e cidadania. A compreensão dessa problemática, dada sua complexidade e seu caráter multidimensional, reclama a construção de perspectivas epistêmicas transdisciplinares, linha que orienta as formulações de Martín-Barbero. Sua investigação requer também a criação de estratégias transmetodológicas, marcadas por atravessamentos de métodos, reformulações e invenções (Maldonado, 2008). Estes desafios nos incitam a continuar trabalhando para construir possibilidades de melhor perspectivarmos estes fenômenos e nos situarmos no campo empírico das novas cidadanias para entender, como nos convida Martín-Barbero, "o que aí soa, fala, grita, insulta, blasfema, ao mesmo tempo que inaugura, inventa, oxigena, libera, emancipa, cria” (2009a, para. 4), constituindo razões para a nossa esperança. $\mathbf{M}$ 


\section{REFERÊNCIAS}

Albuquerque, M. Z. (2018). Entre as redes sociais digitais e as ruas: Processos comunicacionais dos coletivos Defesa Pública da Alegria e Bloco de Lutas (Tese de doutorado, Universidade do Vale do Rio dos Sinos, São Leopoldo, RS, Brasil). Recuperado de http://bit.ly/2ZJUjgM

Bruno, F. (2008). Monitoramento, classificação e controle nos dispositivos de vigilância digital. In H. Antoun (Org.), Web 2.0: Participação e vigilância na era da comunicação distribuída (pp. 167-182). Rio de Janeiro, RJ: Mauad, 2008.

Castells, M. (2013). Redes de indignação e esperança: Movimentos sociais na era da internet. Rio de Janeiro, RJ: Zahar.

Jacks, N. L., \& Schmitz, D. (2018). Os meios em Martín-Barbero: Antes e depois das mediações. MATRIZes, 12(1), 115-130. doi: 10.11606/issn.1982-8160. v12i1p115-130

Jesús Martín-Barbero: 30 anos De los medios a las mediaciones. (setembro/ dezembro 2018). MATRIZes, 12(1). Recuperado de http://bit.ly/2jSHb5O

Lopes, M. I. V. (2018). A teoria barberiana da comunicação. MATRIZes, 12(1), 39-63. doi: 10.11606/issn.1982-8160.v12i1p39-63

Maldonado, A. E. (2008). A perspectiva transmetodológica na conjuntura de mudança civilizadora em inícios do século XXI. In A. E. Maldonado, J. A. Bonin, \& N. M. Rosário (Orgs.), Perspectivas metodológica em comunicação: Desafios na prática investigativa (pp. 27-54). João Pessoa, PB: Editora Universitária da UFBA.

Marchezan, E. (2016). Imersão e agência no webjornalismo: Estratégias narrativas para a produção da grande reportagem multimídia (GRM). In P. Nunes (Org.), Jornalismo em ambientes multiplataforma (pp. 170-183). João Pessoa, PB: CCTA.

Martín-Barbero, J. (1987). De los medios a las mediaciones: Comunicación, cultura y hegemonía. Barcelona, Espanha: Gustavo Gili.

Martín-Barbero, J. (2002). Oficio de cartógrafo: Travesías latinoamericanas de la comunicación en la cultura. Santiago, Chile: Fondo de Cultura Económica.

Martín-Barbero, J. (2003). La globalización en clave cultural: Una mirada latinoamericana. Renglones, 53, 18-33. Recuperado de http://bit.ly/2k03Hde

Martín-Barbero, J. (2006). Tecnicidades, identidades, alteridades: Mudanças e opacidades da comunicação no novo século. In D. de Moraes (Org.), Sociedade midiatizada (pp. 51-79). Rio de Janeiro, RJ: Mauad X.

Martín-Barbero, J. (2009a). Cidadanias em cena: Performance, política e direitos culturais. Hemispheric institute. Recuperado de http://bit.ly/2OrfCPy 
Martín-Barbero, J. (2009b). Culturas/Tecnicidades/Comunicación [Documento de trabalho]. Guadalajara, México: Organización de los Estados Iberoamericanos, 2009b. Recuperado de https://www.oei.es/historico/cultura2/barbero.htm

Martín-Barbero, J. (2009c). Desafios políticos da diversidade. Revista Observatório Itaú Cultural, 8, 153-159. Recuperado de http://bit.ly/32Xavdj

Martín-Barbero, J. (2009d). Cuando la tecnología deja de ser una ayuda didáctica para convertirse en mediación cultural. Revista Electrónica Teoría de la Educación: Educación y Cultura en la Sociedad de la Información, 10(1), 22-31. Recuperado de http://bit.ly/2Yf6qCn

Martín-Barbero, J. (2009e). As formas mestiças da mídia (M. Moura, Entrevistadora). Pesquisa Fapesp, 163, 10-15. Recuperado de http://bit.ly/2YvrgZx

Martín-Barbero, J. (2010a). Caminhamos rumo a uma inteligência coletiva. Revista do Instituto Humanitas Unisinos, 10(335), 27-32. Recuperado de http://bit.ly/2KcmKKs

Martín-Barbero, J. (2010b). Comunicación, espacio público y ciudadanía. Revista Folios, 23b, 37-51. Recuperado de http://bit.ly/2ymqe7s

Martín-Barbero, J. (2010c). Comunicación y cultura mundo: Nuevas dinámicas globales de lo cultural. Signo y Pensamiento, 29(57), 20-34. Recuperado de http://bit.ly/2GPylj1

Martín-Barbero, J. (2011). Reubicando el campo de las audiencias en el descampado de la mutación cultural. In N. Jacks (Ed.), Análisis de recepción en América Latina: Un recuento histórico con perspectivas al futuro (pp. 451-461). Quito, Equador: Ciespal. Recuperado de http://bit.ly/2lWbVnn

Martín-Barbero, J. (2014a). Diversidade em convergência. MATRIZes, 8(2), 15-33. doi: 10.11606/issn.1982-8160.v8i2p15-33

Martín-Barbero, J. (2014b). “Tudo o que sabemos, sabemo-lo entre todos” "aquela segunda oportunidade sobre a terra" - Algumas palavras para não faltar completamente. Revista Lusófona de Estudos Culturais, 2(1), 4-6. doi: $10.21814 /$ rlec.51

Martín-Barbero, J. (2018). Dos meios às mediações: 3 introduções. MATRIZes, 12(1), 9-31. doi: 10.11606/issn.1982-8160.v12i1p9-31

Martín-Barbero, J., \& Rey, G. (2001). Os exercícios do ver: Hegemonia, audiovisual e ficção televisiva. São Paulo, SP: Senac.

Mata, M. C. (1999). De la cultura massiva a la cultura mediática. Diálogos de la comunicación, 56, 80-91.

Mattelart, A., \& Vitalis, A. (2015). De Orwell al cibercontrol. Barcelona, Espanha: Gedisa.

Mediações, trajetos e ensinamentos: tributo a Jesús Martín-Barbero (setembro/ dezembro, 2018). Intertexto, 43. Recuperado de http://bit.ly/2jYe1T1 
Moglen, E. (2012). Manifesto Puntocomunista. In S. L. Martínez (Comp.), Ciberespacio y resistencias. Exploración en la cultura digital (pp. 69-81). Buenos Aires, Argentina: Hekht Libros.

Pariser, E. (2012). O filtro invisível: O que a internet está escondendo de você. Rio de Janeiro, RJ: Zahar.

Peruzzo, C. M. K. (2018). Possibilidades, realidade e desafios da comunicação cidadã na web. MATRIZes, 12(3), 77-100. doi: 10.11606/issn.1982-8160. v12i3p77-100

Porto, H. T. (2019). Processos comunicacionais, identitários e cidadãos: Pataxós em "territórios" de resistências e de utopias (Tese de doutorado, Universidade do Vale do Rio dos Sinos, São Leopoldo, RS, Brasil).

Rancière, J. (2005). A partilha do sensível: Estética e política. São Paulo, SP: Editora 34.

Silveira, S. A. (2006). Hackers, monopólios e instituições panópticas: Elementos para uma teoria da cidadania digital. Líbero, 9(17), 73-78. Recuperado de http://bit.ly/2ZfXidb

Sodré, M. (2006). Eticidade, campo comunicacional e midiatização. In D. de Moraes (Org.), Sociedade Midiatizada (pp. 19-31). Rio de Janeiro, RJ: Maud.

Verón, E. (1997). Esquema para el análisis de la mediatización. Diálogos de la comunicación, 48, 9-17. Recuperado de http://bit.ly/2KdRUkC

Artigo recebido em 14 de maio de 2019 e aprovado em 22 de julho de 2019. 